\title{
Sexual health outcomes for young people in state care: cross-sectional analysis of a national survey and views of social care professionals in Wales
}

\begin{abstract}
This paper draws upon data from two separate studies to consider sexual health outcomes for young people in state care in Wales. Cross sectional analysis of the School Health Research Network Survey (2015) examined sexual health behaviours and outcomes of young people in foster care compared to those living in private households. The findings are contextualised with qualitative data (collected 2016) from social care professionals about their practice experiences of supporting sexual health development and seeking to prevent early pregnancy for young people in state care. Findings suggest that young people in state care in Wales experience poorer sexual health outcomes compared to those not in care. Insights from professionals suggest that whilst the state care system has the potential to identify and respond to young people's needs, its effectiveness can be compromised by issues of resources, value-based judgements related to the age at which young people could and should be sexually active, and individual choice and determinism. It is suggested that statutory monitoring of sexual health related outcomes is required, together with a review of policy and practice 'with', rather than 'for', young people in state care. Finally it is argued that increased attention on the quality as well as the quantity of relationships young people in state care have with carers and professionals may provide a simple but powerful policy approach in continued efforts to secure parity in respect of sexual health and development.
\end{abstract}

\section{INTRODUCTION}

Supporting the reproductive and sexual health of young people is a salient public health issue to ward against a range of adverse social and health outcomes (Young et al. 2016: 2). Young people in state care are recognised as a population vulnerable to poor outcomes: a review of 56 US studies concluded that young people with foster care experience were more likely to engage in risky sexual behaviour, including earlier onset of sexual activity, early pregnancy and repeat pregnancy, sexually transmitted infection and transactional sex (Winter et al. 2016). The evidence base 'is unequivocal about the elevated rate of pregnancy among youth in out-of-home care' (James et al 2009: 991). Although limited by non-representative samples of varying size, studies from Australia (Cashmore and Paxman, 1996), Canada (Turpel-Lafond and Kendall, 2009), Spain (Del Valle et al. 2008; Roca 
et al. 2009), Sweden (Vinnerljung and Sallnäs, 2008), the United States (US) (Oshima, et al. 2013; King et al. 2014; Courtney et al., 2011) and the United Kingdom (UK) (Biehal and Wade, 1996; Dixon et al. 2006; Craine et al 2014) have consistently shown this population to be vulnerable to early pregnancy and parenthood. Moreover, the risk of poor outcomes continues into parenthood, with care-experienced parents more likely to experience compulsory state intervention and/or separation from their children (Courtney et al., 2011; Jackson et al. 2015; Dworsky, 2015; Broadhurst, et al. 2017; Roberts et al. 2017).

The extent to which these outcomes are indicative of those experienced by young people in Wales is unclear as little research relates to Welsh populations (with the exception of Craine et al. 2014 and Roberts et al. 2017). Wales is an important context for research considering its comparatively high rates of children and young people in state care (McGhee et al. 2017). Policy and practice provisions supporting the sexual health and development of young people in state care in Wales are discernible. For example, local authorities in Wales have a legislative duty to ensure the provision of advice and support to children and young people in state care, which may include issues relating to sexuality and sexual health (Welsh Government 2015b). Local authorities and health boards are also required to ensure 'good health care', including initial and annual health assessments for those aged 5 and over (Welsh Government 2015b: 18). Public Health Wales (2016), the national public health agency in Wales, recommends that commissioners and providers ensure access for young people in state care to services offering long acting reversible contraception (LARC, e.g. contraceptive implant, injection or coil), and provide sexual health training and support for carers, health and social care professionals. Whilst such guidance appears appropriate and well-intentioned, little is known about its implementation. This includes the views and experiences of professionals tasked with enacting such directives and ensuring provision for young people in state care. More broadly, teenage pregnancy has been subject to sustained political attention in England and Wales, and efforts to reduce universal rates (Social Exclusion Unit 1999, DfES/DH. 2006, DSCF/DH 2010, Public Health Wales 2016, Welsh Assembly Government 2010, Welsh Government 2012, Department for Education 2015) have demonstrated some success with conceptions currently at the lowest level since 1969 (Office for National Statistics 2016). However the extent to which these policies have impacted on young people in state care in Wales is unknown as there is no statutory requirement to publish conception and pregnancy outcomes for this population (Craine et al. 2014). Similarly, annual reporting of sexually transmitted infections 
has noted that young people are disproportionally affected in comparison with the rest of the population in Wales (Public Health Wales 2017). Yet again, no discrete data is available to determine the extent to which this problem affects care experienced young people.

In the absence of official statistics related to sexual health outcomes, conceptions and parenthood for young people in state care in Wales, this paper makes a contribution to the underdeveloped evidence base. Two separate studies undertaken within [removed for peer review] provided insight into sexual health outcomes and efforts to prevent early pregnancy for young people in state care in Wales. Although neither study was designed specifically for this purpose (see limitations) they nevertheless offered valuable information to answer the following research questions:

- Do young people in state care in Wales experience poorer outcomes in respect of sexual health and development?

- How do professionals reflect on support provision for young people in state care in respect of sexual health and pregnancy prevention?

\section{Methods}

A sequential analysis is presented, drawing on data sets from separate research projects undertaken within the [removed for peer review], and the [removed for peer review] at [removed for peer review]. Firstly, the paper examines the self-reported sexual health behaviours and outcomes of young people in foster care and their counterparts living in private households. A contextualised understanding of the findings is then provided, drawing on qualitative data from social care professionals about their practice experiences of seeking to support sexual health and prevent early pregnancy for young people in state care.

\section{Study One: The School Health Research Network (SHRN) student health and wellbeing survey in Wales} (2015)

\section{Study design and recruitment}

This study uses data collected from the School Health Research Network (SHRN) student health and wellbeing survey in Wales in 2015. A full description of measures and methodology can be found in [removed for peer 
review]. At the time of the 2015 survey, network schools represented just over half $(\mathrm{N}=113 ; 53 \%)$ of all secondary schools in Wales $(\mathrm{N}=212)$, with representation in all 22 local authority areas. Schools were recruited to the network through three mechanisms. Firstly, those participating in the Welsh Health Behaviour in School-aged Children (HBSC) survey in 2013/14 (Welsh Government 2015a) were invited to join (60 out of 82 secondary schools approached joined the network). Secondly, nine schools in South Wales that were recruited to a HBSC sub-study in 2013 to pilot data linkage methods joined the network. Finally, 44 schools joined in 2015 during a period of open recruitment. All network schools were invited to participate in a cross-sectional survey of students between September and December 2015. The survey was an online, closed response, self-completion survey, available in English and Welsh. Schools managed survey implementation using their own IT facilities. Schools were asked to include all students, but if not possible, to include a minimum of two mixed ability classes per year group. Schools were asked to oversee students taking the survey. Staff were asked to remain at the front of the room unless a student asked for help. Schools could opt-out of the sexual behaviour and drug related questions if they chose to.

\section{Measures}

\section{Living arrangements}

Students were asked who they lived with, with options of 'mother,' 'father,' 'step mother,' 'stepfather,' 'foster mother,' 'foster father,' or 'other'. For analysis purposes, a 'living arrangements' variable was created whereby students were classified as living with 'both parents,' a 'single mother,' a 'single father,' in a 'step family,' or in 'foster arrangements'. For regression analysis, data were categorised as 'foster care' vs 'other.'

\section{Sexual health behaviours}

Students were asked if they had ever sent someone a sexually explicit image of themselves, with four response options ('never'; 'once'; 'more than once'; 'I do not want to answer'), and were asked whether anyone else has ever sent, forwarded or shared a sexually explicit image to other people without asking ('yes'; 'no'; 'I do not want to answer'). Students were asked if they had ever had sexual intercourse, and a binary variable was created by assigning 1 to those who said 'yes', and 0 for 'no' responses. 'I don't want to answer', 'refused to answer' 
and missing cases were excluded. Young people who answered yes to having had sex were asked questions on their contraceptive use and age at first intercourse. Students were asked 'how old were you when you had sexual intercourse for the first time?' Respondents answered in single year ages ranging from ' 11 years or younger' up to '18 years or older', with an option 'I don't want to answer', and those who refused to answer recorded. Students were asked whether they used a condom, birth control pills, LARC, emergency contraception or any other form of protection the last time they had sex, with responses of 'yes'; 'no'; 'don't know'; or 'I don't want to answer'. All students were asked questions relating to sending and forwarding sexually explicit images. However, in accordance with the protocol used by the World Health Organization's Health Behaviour of School-aged Children (HBSC) survey, only students in Year 11 (i.e. 15 to 16 year olds) and above (i.e. those attending $6^{\text {th }}$ forms within participating schools, typically aged 16 to 18 years), were asked questions on their sexual behaviour (Currie et al. 2014). Thus, the sample sizes presented for questions on sexual intercourse and contraceptive use are markedly smaller.

\section{Socio-demographic characteristics}

All students indicated their sex, year and month of birth.

\section{Research ethics and consent}

Ethical approval for the survey was granted by [removed for peer review]. Schools returned a registration form indicating their intention to participate in the study. Schools informed parents about the survey using two of three methods (letters sent home with students or via email, and a text message notification about the letter) and parents had the option of withdrawing their child from data collection ('opt-out' consent procedure).

\section{Statistical analyses}

Percentages for each outcome variable are presented, broken down by living arrangements. Missing and 'I do not want to answer' responses were excluded from analyses. To test the significance of associations of living in foster care with sexual health behaviours, binary logistic regression models were constructed. Due to small numbers, some categories were collapsed; for example sending sexually explicit image variable (ever vs. never). For the 
condom use and pill use models, we created binary variables, coding 'yes' responses as ‘0' and 'no' and 'don't know' response as ' 1 '. Age of first intercourse was treated as a continuous variable and analysed using linear regression. Given the ordinal nature of the variable, ordinal and multinomial models were also constructed as form of sensitivity analyses, and as these yielded comparable results, only the linear models are presented. Foster care status was entered as a predictor variable.

\section{Study Two: Early parenthood for young people in and leaving state care in Wales}

The second study is a post-doctoral fellowship project concerned with early parenthood for young people in or leaving state care in Wales. The research plan is outlined in Figure 1.

Figure 1: Early parenthood for young people in and leaving state care in Wales

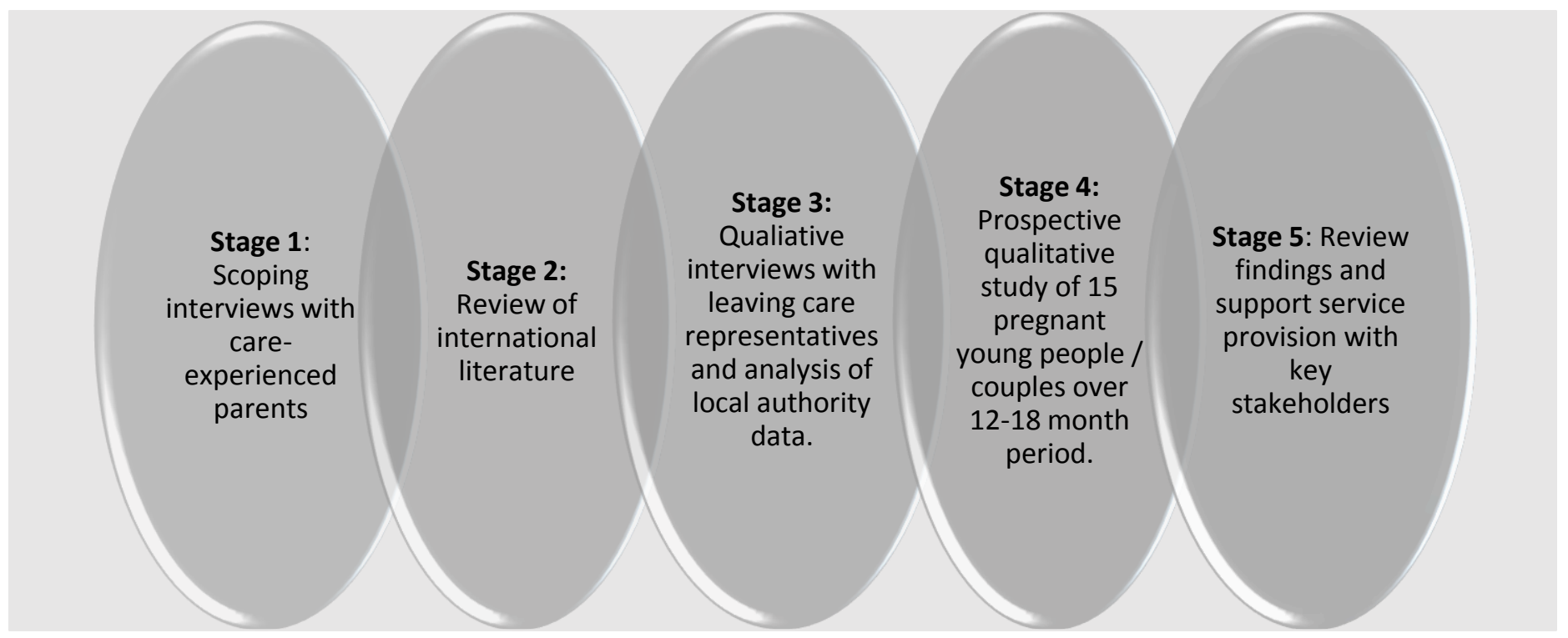

Further details of the study and its findings to date are outlined in [removed for peer review] and [removed for peer review]. This paper draws on qualitative data generated in Stage 3 of the project. Semi-structured interviews were undertaken with representatives of leaving care services from each of the twenty two local authorities across Wales. Ethical approval was granted by [removed for peer review]. The interviews explored professionals' experiences and local responses to pregnancy and parenthood for young people in and leaving state care; this included initiatives designed to prevent or delay pregnancy, as well as respondents' perceptions of risk and 
protective factors. Local authorities were asked to nominate individuals for interview who had interest or expertise in this area. Information sheets and details of the broad areas for discussion were provided prior to interview. Respondents mainly consisted of team managers with responsibility for children in and/or leaving care, but also included a senior manager, senior practitioners, social workers, personal advisors and a 'Looked after Children's' nurse. Of the twenty two interviews, eighteen were conducted with one respondent, three interviews were conducted with two respondents and one with three respondents. All interviews took place within the respondent/s' place of work during 2016 (i.e. shortly after the SHRN survey data collection were complete, but before analyses took place). The interviews ranged from forty-five to ninety minutes duration and each was transcribed verbatim. An inductive thematic approach (Seale 2012) to analysis was adopted whereby interview transcripts were coded and collated, enabling key themes within and across participant data to emerge. For example, 'supporting access to health services', 'specialist programmes', 'recognised professional responsibility for sexual health advice' formed part of the theme 'the system has it covered'. The conduct of interviews and analysis was undertaken by the first author.

\section{RESULTS}

\section{Study One: SHRN student health and wellbeing survey in Wales in 2015}

\section{Sample characteristics}

A total of 87 schools (77\% of the 113 network schools) took part in the 2015 SHRN survey. Mean Free School Meal (FSM) entitlement (a marker of socioeconomic deprivation) was $16.9 \%$ within these 87 schools (national average $=17.8 \%$ ). Schools were also representative of schools in Wales according to academic attainment and school size. Eighteen schools opted to exclude the sexual behaviour questions from the survey. Thirty-six parents and 1137 children opted out of the survey. A total of 35,187 young people completed the survey. Young people who provided sufficient data to categorise their current living arrangements were included in the analyses $(90.1 \%$; $\mathrm{N}=31,696)$. Of these $52.8 \%(\mathrm{n}=16,724)$ were female. Ages ranged from 10.9 to $19.8, \mathrm{M}=13.85(\mathrm{SD}=1.68)$. Students that did not answer the question, or ticked 'I do not want to answer' were removed from the analyses. See table 1 for the sample size for each outcome. 


\section{Sexual health behaviours}

Young people in foster care were significantly more likely to report ever having had sexual intercourse, and to report an earlier age of intercourse (Tables $1 \& 2$ ). Young people in foster care had approximately three times higher odds of not reporting condom use at last intercourse compared to those with a different type of living arrangement (Table 2). Similarly, those in foster care had almost 5 times the odds of reporting use of contraceptive pill at last intercourse. A higher proportion of young people in foster care reported sending a sexually explicit image of themselves or having a sexually explicit image of themselves forwarded without their consent, compared to young people who reported other types of living arrangements (Tables $1 \& 2$ ). 
Table 1: Prevalence of sexual health behaviours by living arrangement

\begin{tabular}{|c|c|c|c|c|c|c|}
\hline & \multicolumn{6}{|c|}{ Living arrangement \%(n) } \\
\hline & $\begin{array}{c}\text { Both parents } \\
(n=20,246)\end{array}$ & $\begin{array}{c}\text { Single mother } \\
(n=5797)\end{array}$ & $\begin{array}{c}\text { Single Father } \\
(\mathrm{n}=798)\end{array}$ & $\begin{array}{c}\text { Step family } \\
(n=4055)\end{array}$ & $\begin{array}{c}\text { Foster parent } \\
(\mathbf{n}=\mathbf{3 1 0})\end{array}$ & $\begin{array}{c}\text { Other } \\
(n=490)\end{array}$ \\
\hline \multicolumn{7}{|c|}{ Ever sent a sexually explicit image } \\
\hline More than once & $4.4(863)$ & $7.2(397)$ & $5.0(38)$ & $8.4(327)$ & $20.3(57)$ & $20.0(90)$ \\
\hline Once & $2.7(537)$ & $4.2(231)$ & $4.1(31)$ & $5.1(200)$ & $5.7(16)$ & $6.7(30)$ \\
\hline Never & $92.9(18,219)$ & $88.7(4,917)$ & $91.0(692)$ & $86.5(3,366)$ & $74.0(208)$ & $73.4(331)$ \\
\hline \multicolumn{7}{|c|}{ Ever had a sexually explicit image forwarded } \\
\hline Yes & $6.2(1,217)$ & $9.1(508)$ & $11.0(83)$ & $10.3(405)$ & $19.9(56)$ & $19.9(91)$ \\
\hline No & $93.8(18,422)$ & $90.9(5,070)$ & $89.0(673)$ & $89.7(3,513)$ & $80.1(225)$ & $80.1(367)$ \\
\hline \multicolumn{7}{|c|}{ Ever had sexual intercourse } \\
\hline Yes & $26.5(925)$ & $35.2(380)$ & $34.6(53)$ & $41.2(306)$ & $65.0(39)$ & $60.7(71)$ \\
\hline \multirow[t]{3}{*}{ No } & $73.5(2,567)$ & $64.9(701)$ & $65.4(100)$ & $58.8(436)$ & $35.0(21)$ & $39.3(46)$ \\
\hline & \multicolumn{6}{|c|}{ Within those who have responded 'yes' to ever had sexual intercourse } \\
\hline & $(\mathbf{n}=925)$ & $(\mathbf{n}=\mathbf{3 8 0})$ & $(\mathbf{n}=53)$ & $(\mathbf{n}=\mathbf{3 0 6})$ & $(\mathbf{n}=39)$ & $(\mathbf{n}=71)$ \\
\hline \multicolumn{7}{|l|}{ Age of first intercourse } \\
\hline 11 years or younger & $2.4(22)$ & $4.3(16)$ & $2.0(1)$ & $2.0(6)$ & $46.2(18)$ & $23.6(16)$ \\
\hline 12 years & $0.9(8)$ & $1.3(5)$ & $4.0(2)$ & $3.4(10)$ & $2.6(1)$ & $1.5(1)$ \\
\hline 13 years & $4.6(42)$ & $8.3(31)$ & $4.0(2)$ & $10.5(31)$ & $7.7(3)$ & $13.2(9)$ \\
\hline 14 years & $18.9(171)$ & $25.0(93)$ & $25.4(13)$ & $23.3(69)$ & $12.8(5)$ & $25.0(17)$ \\
\hline 15 years & $38.2(346)$ & $34.9(130)$ & $35.2(18)$ & $39.2(116)$ & $20.5(8)$ & $23.5(16)$ \\
\hline 16 years & $25.6(232)$ & $19.6(73)$ & $21.6(11)$ & $18.0(53)$ & $10.3(4)$ & $11.8(8)$ \\
\hline 17 years or older & $8.6(78)$ & $6.4(24)$ & $5.9(3)$ & $3.4(10)$ & $0.0(0)$ & $1.5(1)$ \\
\hline \multicolumn{7}{|c|}{ Contraception at last intercourse } \\
\hline \multicolumn{7}{|c|}{ Condom } \\
\hline Yes & $52.8(477)$ & $43.2(158)$ & $54.0(121)$ & $40.5(121)$ & $23.1(9)$ & $30.0(21)$ \\
\hline No & 43. (388) & $52.5(192)$ & $36.0(18)$ & $56.5(169)$ & $61.5(24)$ & $60.0(42)$ \\
\hline Don't know & $4.2(38)$ & $4.4(16)$ & $10.0(5)$ & $3.0(9)$ & $15.4(6)$ & $10.0(7)$ \\
\hline \multicolumn{7}{|l|}{ Birth control pill } \\
\hline Yes & $39.0(355)$ & $45.4(169)$ & $42.3(22)$ & $49.3(148)$ & $13.5(5)$ & $38.6(27)$ \\
\hline No & $54.5(497)$ & $48.4(180)$ & $50.0(26)$ & $45.0(135)$ & $64.9(24)$ & $55.7(39)$ \\
\hline Don't know & $6.6(60)$ & $6.2(23)$ & $7.7(4)$ & $5.7(17)$ & $21.6(8)$ & $5.7(4)$ \\
\hline \multicolumn{7}{|c|}{ Long Acting Reversible Contraception (LARC) } \\
\hline Yes & $15.2(138)$ & $19.1(70)$ & $13.5(7)$ & $21.7(65)$ & $8.1(3)$ & $20.6(14)$ \\
\hline No & $76.3(692)$ & $74.1(272)$ & $75.0(39)$ & $67.9(203)$ & $75.7(28)$ & $64.7(44)$ \\
\hline Don't know & $8.5(77)$ & $6.8(25)$ & $11.5(6)$ & $10.4(31)$ & $16.2(6)$ & $14.7(10)$ \\
\hline \multicolumn{7}{|c|}{ Emergency contraception } \\
\hline Yes & $6.9(63)$ & $10.3(38)$ & $8.0(38)$ & $8.0(24)$ & $8.1(3)$ & $12.9(9)$ \\
\hline No & $86.4(788)$ & $85.6(316)$ & $80.0(40)$ & $81.0(243)$ & $75.7(28)$ & $77.1(54)$ \\
\hline Don't know & $6.7(61)$ & $4.1(15)$ & $12.0(6)$ & $11.0(33)$ & $16.2(6)$ & $10.0(7)$ \\
\hline \multicolumn{7}{|l|}{ Other } \\
\hline Yes & $19.7(178)$ & $23.4(86)$ & $24.5(12)$ & $19.9(60)$ & $18.9(7)$ & $16.9(12)$ \\
\hline
\end{tabular}




\begin{tabular}{|c|c|c|c|c|c|c|}
\hline No & $74.1(668)$ & $72.0(265)$ & $69.4(34)$ & $71.8(216)$ & $73.0(27)$ & $74.7(53)$ \\
\hline Don't know & $6.2(56)$ & $4.6(17)$ & $6.1(3)$ & $8.3(25)$ & $8.1(3)$ & $8.5(6)$ \\
\hline
\end{tabular}

Table 2: Odds Ratios (95\% confidence intervals) for the association between foster care and sexual health behaviours (all p-values are <0.001)

\begin{tabular}{|l|c|c|}
\hline & n included in model & Foster care \\
\hline Ever sent sexually explicit image & $\mathbf{n = 3 0 , 0 5 0}$ & $3.63(2.77-4.78)$ \\
\hline Ever had a sexually explicit image forwarded & $\mathbf{n = 3 0 , 1 2}$ & $3.11(2.36-4.11)$ \\
\hline Ever had sexual intercourse & $\mathbf{n = 5 , 5 2 3}$ & $-2.25(2.47-7.29)$ \\
\hline Age of first intercourse & $\mathrm{n}=1,661$ & $(-2.54-1.45)$ \\
\hline Contraception at last intercourse & & \\
\hline No condom use at last intercourse* & $\mathbf{n = 1 , 6 2 5}$ & $3.12(1.70-5.76)$ \\
\hline No pill use at last intercourse* & $\mathbf{n = 1 , 6 6 8}$ & $4.72(1.97-11.28)$ \\
\hline
\end{tabular}

*No categories include 'don't know' responses 


\section{Study Two: Early parenthood for young people in and leaving state care in Wales}

The results in the previous section provide evidence of poorer outcomes for young people in state care in Wales, in respect of sexual health and development. The results provide a valuable backdrop from which to consider the perspectives and views of leaving care professionals regarding efforts and challenges to ensuring effective sexual health support. The following section presents the key themes emergent from the professional interviews and offers a contextualised understanding of what accounts for the disparity in outcomes.

\section{The system has it covered: Professional confidence in available support and expertise}

While the SHRN analysis indicated poorer sexual health outcomes for young people in care, professional respondents frequently described a robust state care system, adept at identifying and responding to young people's sexual health needs. Repeated references were made to procedural and recording obligations which ensured periodic consideration of sexual health and contraception needs:

...sexual health, contraception, knowledge of sexual health clinics, it's all covered as part of the pathway planning process (Senior Practitioner LA 18).

The pathway plan asks whether or not they are aware of, or have access to sex education, they know how to access birth control ... we make sure that they have been told about it, they've learnt about it at school, the 'looked after' nurse has been out to see them (Team manager LA 9)

In this way, there was broad acknowledgement that supporting young people in regards to sexual health and contraception was shared amongst those involved with the young person. A sense of collective professional responsibility in respect of sexual health and development for young people in state care has also been acknowledged in previous research, but this has also recognised the potential for such responsibility to be diffused or diluted with the involvement of multiple professionals (Chase et al. 2009, Constantine 2009, Hyde et al. 2016). This potential was not acknowledged by Welsh professionals. Residential workers and foster carers were recognised as important figures in this regard and a possible key source of support for young people. As noted by one team manager: "ideally the carers will do it in a natural environment" (LA 4) as this was more akin to the support ordinarily provided within families. Previous research has acknowledged that carers can be unclear about their role and responsibility in respect of providing sexual health advice (Knight et al. 2006, Corylon and McGuire 1999). Although one respondent did highlight some variation in carers' ability to deliver this support, this was 
not evident in other interviews and respondents generally did not single out carers as having primary responsibility for sexual health. Rather, carers, personal advisors and social workers were all seen as well placed to engage young people in discussions regarding relationships, sexual health and contraception:

Within our residential work, residential workers are trained up to sexual health with our young people and I'd like to say that all our social workers and personal advisors sort of do that within their role ... I'd like to think that that's always covered in core assessments and just general sort of social work.

(Team Manager LA 2)

We do expect the carers whether they be foster carers or residential staff to address, work with them but the social workers obviously have got a responsibility to be talking about the sexual health and you know ways to prevent pregnancy but also safe sex. (Team Manager LA 4)

Personal advisors do it [discuss sexual health and development issues] and the social workers ... it's part of our general informal conversations that you tend to have in that relationship building period with the kids as well you know 'oh how is so-and-so' 'oh you better be safe' you know, 'do you want to talk about that', 'do you have a plan', you know 'have you got contraception', 'do you want support with that' or 'would you prefer us to have a conversation with your foster carer'? They're the type of things that we do quite routinely I'd say. (Senior Practitioner LA 1)

In addition, the 'Looked after Children's' nurse was viewed as an important resource, able to offer specialist knowledge and confidential advice:

[The nurse] goes out as part of her role to speak to them when they sort of hit sort of well, before puberty, whatever level we feel it is and does some sort of workbooks with them, does discussions with them and does it on whatever level she recognises their development to be. She will support them going to clinics you know and, and do whatever she feels that you know they want to do about contraception and knowing that sort of stuff. (Senior Practitioner LA 7)

[The nurse] takes them to clinic, she takes them, she reminds them when things need to be done. And yeah she is very experienced in obviously promoting safe sex etcetera. (Team manager LA 11)

I suppose the first and the most important person we have is the 'Looked after Children's' nurse ... they'll get all the review documentation and if they pick up on any issues that relate to sort of health and sexual health then you know they pick it up and run with it. (Senior Practitioner LA 5)

Participants also described a range of local approaches and initiatives designed to ensure young people's needs were met. Examples included the use of the crying dolls, outdoor pursuits activities designed to boost selfesteem, information and discussion sessions, as well as outreach and fast-tracked sexual health appointments. Whilst there was variety in local approaches and initiatives, respondents broadly described a comprehensive 
system of support, whereby attempts to engage, inform and advise young people in respect of sexual health and contraception was part of routine and embedded practice.

\section{Threats to the system}

The perspectives of professionals above are somewhat at odds with the disparities highlighted in study one. Yet despite respondents' confidence in the potential of the state care system to recognise and respond to young people's sexual health needs, a series of threats were acknowledged which challenged effective practice and positive outcomes.

\section{- Limited resources}

Several respondents complained about funding cuts and austerity measures which impacted on service provision. Describing pregnancy prevention initiatives within the area, one respondent noted: 'I'm not quite sure if that's changing ... everything always is in flux and you know with cutbacks things change' (Senior Practitioner LA 5). Similarly, describing the impact of funding and organisational restructuring, Senior Practitioner (LA 16) stated:

we used to do like a drop-in day, ... we would do an open day, we'd talk about sexual health in the morning and then we'd go and do an activity in the afternoon ... but we haven't done it for over a year or so, ... it's funding stopping and just not having the time... There was a time when it was regular but at the minute everything is up in the air because it's all changed, everyone is bogged down, we're not having these event days...

Related to this, a personal advisor commented: "The LAC nurse has run a few sort of courses with the dolls and things ... but I'm not aware that's happened for a while now ... (LA 20). Other respondents also raised concerns about the limited availability and capacity of Looked after Children's nurses, including restricted access or shared resources with neighbouring authorities. This was the experience of the Looked After Children's nurse that participated in the interviews, who acknowledged changes to her role which had curtailed the extent of support previously provided; "until recently you know I would physically support young people in going to youth advisory clinics for implants" (LA 10).

Viewed in this way, the effectiveness of state care system in respect of sexual health was dependent upon sufficient resources and sexual health support appeared to have deteriorated as a consequence of funding pressures. 


\section{- 'Responsible' corporate parenting}

Value-based dilemmas were raised by other professionals. Most notably this was in regard to questions as to when young people should be provided with sexual health information and advice. Several participants discussed experiences of supporting young people who were known or suspected of being sexually active before the legal age of consent. Previous research has highlighted this as an area of uncertainty for professionals due to the lack of organisational policy and guidance (Constantine et al. 2009; Hyde et al. 2015). Comparable tensions were evident in this research. For example, concerns not to be seen to promote or sanction engagement in sexual activity before the age of consent were apparent, with one respondent commenting that senior management officials were 'a little bit twitchy if it's someone under 16 with contraception (Team Manager LA 10). Likewise, in an effort to avoid introducing young people to issues related to sex and relationships before they were ready, one respondent stated 'ideally it's addressed from a younger age but I think quite often in reality what happens is we wait until they become perhaps sexually active before we tend to address' (Team Manager LA 4).

Such comments highlight an inherent tension between seeking to pre-empt known risks, whilst at the same time being conscious not to prematurely prompt, encourage or condone early onset of sexual activity.

\section{- Individual risk factors}

Finally, respondents highlighted the limits to which the state care system could influence individual choice and behaviour. For example, several respondents differentiated between ensuring young people had the necessary information and advice, and the extent to which young people acted on the information provided:

I'd say they know, their knowledge is quite good ... they seem to be getting the information but actually doing something about it or using something [contraception], not that good. (Senior practitioner LA 19)

...for me in my experience when I was a practitioner, it wasn't about young people not knowing about contraception, they know about contraception, it was more about how to initiate the use of that contraception in their relationships. It was more about I know I should be using contraception or condoms and practising safe sex but I don't know how to insist that happens in the heat of the moment. (Team Manager LA 12)

The above quotations highlight the importance of broader preventative initiatives aimed at promoting healthy relationships and self-esteem. In addition, respondents identified a range of individual risk factors based on their 
professional experience which suggested young people were more likely to be young parents. Corresponding with previous research findings these included young people who had experienced unstable placements, were in serious relationships, were involved in risky sexual behaviour and / or had few educational and career aspirations (see reviews by Connolly et al. 2012; Svoboda et al. 2012). Similarly, the potential for early pregnancy and parenthood to be viewed positively by young people (Connolly et al. 2012) was also identified by the majority of respondents in this research:

I think young people who have been through the looked after children system tend to crave those attachments and that family at a younger age to a higher level than the general population. (Team manager LA 13)

I think it's about belonging and attachment and yeah wanting to be loved and feel loved and maybe some sort of sense of belonging and purpose. (Team manager LA 12)

Yeah I think for certainly my experience of working with young girls in particular is there can be quite often this idea of loss, bereavement and the urge to become a parent to kind of satisfy that loss ... that can certainly be a trigger for pregnancies and certainly repeated pregnancies. (Team manager LA 14)

I just think sometimes they want someone to love unconditionally, someone that's going to be there. They don't think sometimes of the consequences of that decision making which is why we try to do that early intervention and that preventative work. And they want that, they want that security in a relationship, somebody is just going to need them unconditionally (Senior Practitioner LA 1)

While the state care system provides access to sexual health information and advice, the comments above emphasise the influence of young people's experiences before and during state care. Such experiences have the potential to wield powerful influence over individual behaviour and choice, regardless of the provision of sexual health advice.

\section{DISCUSSION}

The aim of this paper was to make a contribution to the underdeveloped evidence base in respect of sexual health development and outcomes for young people in state care in Wales. The paper has demonstrated poorer outcomes for young people in foster care (study one), who in comparison with their peers, were more likely to report having had sexual intercourse, to have started having intercourse at an earlier age and were least likely to report use of contraception at last intercourse. The additional vulnerabilities of young people in foster care were further 
highlighted through consideration of digital media which demonstrated both a higher incidence of sending sexually explicit images of themselves, as well as having such images distributed without their consent. The consistency of poorer outcomes for young people in foster care compared to young people across a range of living arrangements elucidates the extent of disadvantage. Despite substantial reductions in recorded teenage conceptions in Wales (1996-2015) (Stats Wales 2017), our findings add weight to Fallon and Broadhurst's (2015: 13) assertion that "whilst rates of overall adolescent births have been declining in a number of high resource countries, young people with a care history remain at elevated risk'.

Qualitative data from leaving care professionals across Wales (study two) provided some context to explain the disadvantaged position of young people in foster care. Somewhat in contrast to the findings suggesting poorer outcomes, the analysis portrayed a general confidence in the potential of the state care system to identify and respond to young people's sexual health needs. Interviews depicted the state care system as encapsulating a multitude of professionals and carers whose expertise, networks and professional mandates ensured access to information and support in respect of sexual health. However the effectiveness of the system was perceived to be undermined by finite resources and limited professional capacity, as well as value-based judgments about the age at which young people could and should be sexually active. Importantly, the perspectives of leaving care professionals emphasised individual choice and determinism. In this way, the state care system was seen as effectual for young people able and willing to access and act upon available information. However, there were limits to which the system could counteract ambivalence or active pregnancy planning.

Such insights resonate with the wider literature. For example, previous concerns have been raised about the availability and capacity of Looked after Children's nurses to provide specialist sexual health advice and support (Lyons et al. 2014, RCN 2015). The potential influence of moral and value judgements has been identified by service providers in Ireland (Hyde et al. 2015). Likewise, Robertson (2013: 498) noted the potential for child welfare policies to be silent in regards to sexual health and support, and argued there is a need to accept 'that adolescents in foster care are sexual beings'. Similarly, the evidence base has long made connections between emotional well-being and early pregnancy, (see reviews by Connolly et al. 2012, Svoboda et al. 2012) and noted 
the potential for young people to associate early parenthood with stability, family, closeness and love (Connolly et al. 2012).

\section{Limitations}

Several limitations are acknowledged. Firstly, while interview respondents were all connected to local authority leaving care services, there was much variety in individuals' roles and responsibilities. This likely influenced the data generated within the study and it cannot be assumed to be representative of the practice or perspectives across authorities.

The cross-sectional design of the SHRN study means that causality cannot be established; common issues are likely to be associated both with risky behaviours and entry to foster care, while the sequencing of these issues (i.e. whether sexual risk behaviours were established prior to or after entry to care) is unclear. While most measures are adopted from previous surveys, including the international World Health Organization's Health Behaviour of School-aged Children survey, some have not been widely used previously and measures relating to sexually transmitted infections were not included. The sensitivity of some of the topics may have led to underreporting. Sexual health questions were asked only of students aged 15 and above in 2015 (although following requests from schools, will be extended to lower age groups in subsequent years). Combined with the small subsample of young people in foster care, statistical modelling was not possible for all outcomes, and we presented only crude unadjusted statistical models due to limited power. Analyses of future SHRN data rounds with expanded sample sizes will enable consideration of the sexual health and development of young people living in foster care with those in a variety of private living arrangements. Further research with larger samples could provide more nuanced insights into variations according to experiences of care, such as comparisons between kinship and residential placements, and variations in sexual health behaviour and outcomes by age of entry, length of care experience and / or number of care episodes. In addition, young people in state care face many barriers in education and are vulnerable to disruption and exclusion (Mannay et al. 2015). As such, it would have been preferable to have enabled opportunities for participation to young people in education settings other than mainstream schooling. Notably, the research team plan to address these issues in future rounds of the survey, 
as well as include unique identifiers to enable longitudinal analyses of trajectories in care among secondary school aged children.

\section{Conclusion}

The findings of this paper suggest renewed policy and practice is required to address the poorer outcomes for young people in state care in respect of sexual health. In their consideration of 'Can the corporate state parent?', Bullock et al. (2006) recognise the state care system is 'an impersonal entity' and that tasks in relation to parenting are provided at national, local and personal levels, and shared across a number of individuals. This depiction provides a useful way to consider means of monitoring and improving the effectiveness of the state as a parent in respect of sexual health and avoidance of early pregnancy. At a national level, the findings underscore the importance of continued monitoring of sexual behaviour outcomes and add weight to previous calls for statutory reporting of conception and pregnancy outcomes for young people in state care (Craine et al. 2014). Similarly, the recently implemented Social Services and Well-Being Act 2014 in Wales is underpinned by principles of coproduction, prevention and well-being. We contend that this legislative framework provides a promising foundation from which to review and develop sexual health policy and practice 'with' rather than 'for' young people in state care. Previous research has repeatedly emphasised the importance of learning from and being led by young people, identified concerns for privacy, deficits in supportive networks, and highlighted the need to improve access to appropriate sex education and sexual health advice (Corylon and McGuire 1999; Love et al. 2005; Chase et al. 2009; James et al. 2009; Connolly et al. 2012; Svoboda et al. 2012; Aparicio et al. 2015; Ahrens et al. 2016; Hyde et al. 2015; Winter et al. 2016). Likewise, best practice guidelines have sought to overcome divergent views of young people and professionals in respect to the delivery of sex education (Pound et al. 2017) and extending this work with specific reference to the needs of young people in state care would likely be beneficial. The poorer sexual health outcomes highlighted in this paper, combined with the depiction of some young people, consciously or unconsciously, seeking to fulfil unmet relational needs through sexual relationships, early pregnancy and parenthood should not be interpreted as beyond the limits of state care influence. In contrast, we argue that the findings emphasise the importance of relational quality, as well as the quantity of carers and professionals available to offer sexual health advice. At a personal level, ensuring the state is getting right 'the 
basics' (Children's Commissioner for Wales 2016) where young people enjoy close, trusting relationships with carers, have ease of access and positive, consistent relationships with supporting individuals, may be a simple but powerful policy approach in efforts to create parity for young people in respect of sexual health outcomes and pregnancy prevention.

\section{References}

Ahrens, K. R.; Spencer, R.; Bonnar, M.; Coatney, A. and Hall, T. 2016. Qualitative evaluation of historical and relational factors influencing pregnancy and sexually transmitted infection risks in foster youth. Children and Youth Services Review, 61, 245-252.

Aparicio, E.; Pecukonis, E. V. and O'Neale, S. 2015. “The love that I was missing”: Exploring the lived experience of motherhood among teen mothers in foster care. Children and Youth Services Review, 51, 44-54

Biehal, N. and Wade, J. (1996) Looking back, looking forward: care leavers, families and change. Children and Youth Services Review, 18, 4-5, 425-445.

Broadhurst, K., Mason, C. and Bedston, S. (2017) What are our obligations to care leavers who lose their own infants and children to the State? [Online]. http://wp.lancs.ac.uk/child-and-family-justice/2017/03/01/careleavers-children/ (Accessed 8.4.17).

Bullock, R., Courtney, M. E., Parker, R., Sinclair, I. and Thoburn, J. (2006) Can the corporate state parent? Children and Youth Services Review, 28, 11, 1344-1358.

Cashmore, J. and Paxman, M. (1996). Wards leaving care: A Longitudinal study.

Sydney: NSW Department of Community Services.

Chase, E., Warwick, I, Knight, A. and Aggleton, P. (2009) Supporting Young Parents: Pregnancy and parenthood among young people from care. London: Jessica Kingsley

Children's Commissioner for Wales (2016a) Children in our Care - let's get the basics right. WWW. http://www.childcomwales.org.uk/about-us/sallys-blog/children-care-lets-get-basics-right/ Published August 2016.

Connolly, J., Heifetz, M. and Bohr, Y. (2012) 'Pregnancy and motherhood among adolescent girls in child protective services: a meta-synthesis of qualitative research', Journal of Public Child Welfare, 6, 614-635.

Constantine, W. L., Jerman, P. and Constantine, N. A. (2009) Sex Education and Reproductive Health Needs of Foster and Transitioning Youth in Three California Counties. Oakland: Center for Research on Adolescent Health and Development Public Health Institute.

Corylon, J and Maguire, C. (1999) Pregnancy and Parenthood. The views and experiences of young people in public care. London: National Children's Bureau.

Courtney, M., Dworsky, A., Brown, A., Cary, C., Love, K., \& Vorhies, V. (2011). Midwest evaluation of the adult functioning of former foster youth: Outcomes at age 26. Chicago, IL: Chapin Hall at the University of Chicago. 
Craine, N., Midgley, C., Zou, L., Evans, H., Whitaker, R., Lyons, M. (2014). Elevated teenage conception risk amongst looked after children; a national audit. Public Health, 128, 7, 668-670

Currie C, Inchley J, Molcho M, Lenzi M, Veselska Z \& Wild F (eds.) (2014). Health Behaviour in School-aged Children (HBSC) Study Protocol: Background, Methodology and Mandatory items for the 2013/14 Survey. St Andrews: CAHRU.

Del Valle, J. F., Bravo, A., Alvarez, E. and Fernanz, A. (2008) Adult self-sufficiency and social adjustment in care leavers from children's homes: a long-term assessment. Child \& Family Social Work, 13: 12-22.

Department for Education and Skills and Department of Health (2006) Teenage Pregnancy Next Steps: Guidance for Local Authorities and Primary Care Trusts on Effective Delivery of Local Strategies. WWW. http://lx.iriss.org.uk/sites/default/files/resources/Teenage\%20pregnancy\%20next\%20steps.pdf

Department for Children, Schools and Families and Department of Health (2010) Teenage Pregnancy Strategy: Beyond 2010. WWW.

https://www.education.gov.uk/consultations/downloadableDocs/4287_Teenage\%20pregnancy\%20strategy_aw 8.pdf. (Accessed 7.8.17)

Department for Education (2015) Promoting the health and well-being of looked-after children. Statutory guidance for local authorities, clinical commissioning groups and NHS England.

https://www.gov.uk/government/uploads/system/uploads/attachment_data/file/413368/Promoting_the_health_a nd_well-being_of_looked-after_children.pdf (Accessed 30.1.17)

Dixon, J., Wade, J., Byford, S., Weatherly, H. and Lee, J., (2006) Young people leaving care: a study of outcomes and costs. York: Social Work Research and Development Unit.

Dworsky, A. (2015) 'Child Welfare Services Involvement among the children of young parents in foster care' Child Abuse \& Neglect, 45: 68-79.

Fallon, D. and Broadhurst, K. (2015) Preventing Unplanned Pregnancy and Improving Preparation for Parenthood for Care-Experienced Young People. London: Coram.

Hyde, A., Fullerton, D., McKeown, C., Dunne, L., Lohan, M., and Macdonald G. (2015) Sexual Health and Sexuality Education Needs Assessment of Young People in Care in Ireland (SENYPIC): The Perspectives of Key Service-Providers: A Qualitative Analysis. Report No. 3. Dublin: HSE Crisis Pregnancy Programme and Child \& Family Agency (Tusla).

Jackson Foster, L. J., Beadnell, B. and Pecora, P. J. (2015) Intergenerational pathways leading to foster care placement of foster care alumni's children. Child \& Family Social Work, 20: 72-82. doi:10.1111/cfs.12057.

James, S.; Montgomery, S. B.; Leslie, L.K. and Zhang, J. 2009. Sexual risk behaviors among youth in the child welfare system Children and Youth Services Review 31, 9, 990-1000

King, B., Putnam-Hornstein, E., Cederbaum, J. A. and Needell, B. (2014) A cross-sectional examination of birth rates among adolescent girls in foster care. Children and Youth Services Review, 36, 179-186, http://dx.doi.org/10.1016/j.childyouth.2013.11.007.

Knight, A., Chase, E. and Aggleton, P. (2006) Teenage pregnancy among young people in and leaving care: messages and implications for foster care. Adoption \& Fostering, 30 (1), 58-69.

Long, S., Evans, R., Fletcher., A., Hewitt, G., Murphy, S., Young, H. and Moore, G. (2017) A comparison of substance use, subjective wellbeing and interpersonal relationships among young people in foster care and private 
households: a cross sectional analysis of the School Health Research Network survey in Wales. BMJ Open, in press.

Love, L.T., McIntosh, J., Rossi, M. and Tertzakian, K. (2005) Fostering Hope: Preventing teen pregnancy among youth in foster care. Washington D.C.: National Campaign to Prevent Teen Pregnancy

Lyons, M., Couzens, Z., Craine, N., Andrews, S. and Whitaker, R. (2016) Looked after children, care leavers and risk of teenage conception; findings from Wales: Summary of a National Response. CASCADE Briefing WWW. http://sites.cardiff.ac.uk/cascade/files/2014/10/Briefing-6.pdf Accessed 20.10.17

Mannay, D., Staples, E., Hallett, S., Roberts, L., Rees, A., Evans, R. and Andrews, D. 2015. Understanding the educational experiences and opinions, attainment, achievement and aspirations of looked after children in Wales. Cardiff: Welsh Government.

McGhee, J. Bunting, L., McCartan, C., Elliott, M., Bywaters, P. and Featherstone, B. Looking After Children in the UK-Convergence or Divergence?, The British Journal of Social Work, published online 22.8.17

Office for National Statistics (2017) Conceptions in England and Wales: 2015. WWW.

https://www.ons.gov.uk/peoplepopulationandcommunity/birthsdeathsandmarriages/conceptionandfertilityrates/ bulletins/conceptionstatistics/2015\#the-under-18-conception-rate-in-2015-is-the-lowest-recorded-sincecomparable-statistics-were-first-produced (Accessed 7.8.17)

Oshima, K. M., Narendorf, S. C. and McMillen, J. C. (2013) Pregnancy risk among older youth transitioning out of foster care. Children and Youth Services Review 35, 10, 1760-1765.

Pound, P., Denford, S., Shucksmith, J., Tanton, C., Johnson, A., Owen, J., Hutten, R., Mohan, L., Bonell, C., Abraham, C. and Campbell, R. (2017) 'What is best practice in sex and relationship education? A synthesis of evidence, including stakeholders’ views'. BMJ Open, vol 7.

Public Health Wales (2016) Reducing Teenage Conception Rates in Wales: Project Report. WWW. http://www.wales.nhs.uk/sitesplus/documents/888/Teenage\%20conceptions\%20in\%20Wales\%20\%20FINALV 1.pdf (Accessed 12.3.17)

Public Health Wales (2017) HIV and STI trends in Wales. Surveillance Report, June 2017. WWW. http://www.wales.nhs.uk/sitesplus/888/news/45989 (Accessed 11.11.17)

Roberts, L. (2017) A small-scale qualitative scoping study into the experiences of looked after children and care leavers who are parents in Wales. Child \& Family Social Work 22 (3), pp. 1274-1282.

Roberts, L., Meakings, S., Smith, A., Forrester, D. and Shelton, K. (2017) Care leavers and their children placed for adoption. Children and Youth Services Review, published online 17 June 2017.

Robertson, R. D. 2013. The invisibility of adolescent sexual development in foster care: Seriously addressing sexually transmitted infections and access to services. Children and Youth Services Review 35, 3, 493-504.

Roca, J.S., García, M.J., Biarnés, A.V. and Rodríguez, M., (2009) Analysis of factors involved in the social inclusion process of young people fostered in residential care institutions. Children and Youth Services Review, 31(12), pp.1251-1257.

Royal College of Nursing. (2015) RCN survey of nurses working with looked after children. WWW. https://www2.rcn.org.uk/_data/assets/pdf_file/0010/608932/004-735.pdf Accessed 26.1.17

Seale, C. (2004) Coding and analysing data. In: Researching Society and Culture 2nd edn (ed. C. Seale), pp. 305-323. London: SAGE. 
Social Care Institute for Excellence (2004) Preventing teenage pregnancy in looked after children, [Online] http://www.scie.org.uk/publications/briefings/briefing09/ (Accessed 8.4.17, 2004).

Social Exclusion Unit (1999) Teenage pregnancy. London: HMSO.

Stats Wales 2017 Coceptions by year and age group. WWW. https://statswales.gov.wales/Catalogue/Healthand-Social-Care/Births-Deaths-and-Conceptions/Conceptions/conceptions-by-year-agegroup Accessed 25.8.17.

Svoboda, D. V., Shaw, T.V., Barth, R. P. and Bright, C. L. (2012) Pregnancy and Parenting among youth in foster care: A review. Children \& Youth Services Review 34, 867-875.

Turpel-Lafond, M. E., and Kendall, P. (2009) Kids, crime and care - Health and well-being of children in care: Youth justice experiences and outcomes. British Columbia, Canada: Office of the Provincial Health Officer.

Vinnerljung, B. and Sallnäs, M. (2008). Into adulthood: a follow-up study of 718 young people who were placed in out-of-home care during their teens. Child \& Family Social Work, 13: 144-155.

Welsh Government (2010) Sexual Health and Wellbeing Action Plan for Wales 2010-2015. Cardiff; Welsh Government

Welsh Government (2012) Tackling Poverty Action Plan 2012-2016, [Online] http://www.senedd.assembly.wales/documents/s500001880/CELG4-20-14\%20Paper\%205.pdf (Accessed 8.4.17).

Welsh Government (2015a) Health behaviour in school-aged children. http://gov.wales/statistics-andresearch/health-behaviour-school-aged-children/?lang=en (Accessed: 31.08.16)

Welsh Government (2015b) Social Services and Well-being (Wales) Act 2014. Part 6 Code of Practice (Looked After and Accommodated Children). http://gov.wales/docs/phhs/publications/160106pt6en.pdf (Accessed 24.11.16)

Winter, V. R., Brandon-Friedman, R. A. and Ely, G. E. (2016) Sexual health behaviors and outcomes among current and former foster youth: A review of the literature. Children and Youth Services Review 64, 1-14

Young, H., Költő, A., Reis, M., Saewyc, E. M., Moreau, N., Burke, L., Cosma, A., Windlin, B., Gabhainn, S. N. and Godeau, E. (2016) Sexual Health questions included in the Health Behaviour in School-aged Children (HBSC) Study: an international methodological pilot investigation. BMC Medical Research Methodology $16: 169$ 